\title{
Nerve Monitoring for Transoral Thyroid Surgery: Why, How, and What to Expect
}

\author{
Daqi Zhang ${ }^{1,2} \cdot$ Carmelo Mazzeo $^{3} \cdot$ Gianlorenzo Dionigi $^{4} \cdot$ Che-Wei Wu $^{5,6} \cdot$ Paolo Carcoforo $^{7} \cdot$ Hui Sun ${ }^{1,2}$. \\ Gabriele Materazzi ${ }^{8} \cdot$ Ralph P. Tufano $^{9} \cdot$ Hoon Yub Kim ${ }^{10}$
}

Published online: 2 August 2019

(C) Springer Science+Business Media, LLC, part of Springer Nature 2019

\begin{abstract}
Purpose of Review We primarily describe technical tips, and attempt to demonstrate the value of using intermitted neural monitoring (IONM) during transoral endoscopic thyroidectomy vestibular approach (TOETVA), with emphasis and respect given to nerve monitoring standards described by the International Neural Monitoring Study Group (INMSG).

Recent Findings Any modifications to the established operative technique for TOETVA should result in similar or improved patient outcomes with lower rates of complications. TOETVA is a new technique that demands full protection of RLN function during the cranial to caudal thyroid and RLN dissection. Standardized IONM is feasible and safe in TOETVA. IONM is complementary to the video-endoscopic identification of the RLN.

Summary The role of IONM in transoral thyroid surgery continues to be defined. It may be that as one starts performing this surgery, intermittent IONM may provide value in confirming and preserving the neurophysiologic integrity of the RLN. Further studies are needed to evaluate this.
\end{abstract}

Keywords Thyroid · Thyroidectomy · Minimally invasive thyroidectomy $\cdot$ Transoral thyroidectomy $\cdot$ Intraoperative neural monitoring $\cdot$ Standardization

This article is part of the Topical Collection on Transoral Thyroid and Parathyroid Surgery

Carmelo Mazzeo

dott.carmelomazzeo@gmail.com

$\triangle$ Hui Sun

thyroidj1@163.com

1 Division of Thyroid Surgery, China-Japan Union Hospital Of Jilin University, Jilin Provincial Key Laboratory Of Surgical Translational Medicine, Changchun City, Jilin Province, China

2 Jilin Provincial Precision Medicine Laboratory of Molecular Biology and Translational Medicine on Differentiated Thyroid Carcinoma, 126 Xiantai Blvd, Changchun City, China

3 Division of General Surgery and Emergency Surgery, Department of Human Pathology, Department of Human Pathology in Adulthood and Childhood "G. Barresi”, University Hospital G. Martino, Via C. Valeria 1, 98125 Messina, Italy

4 Division of Endocrine and Minimally Invasive Surgery, Department of Human Pathology, Department of Human Pathology in Adulthood and Childhood "G. Barresi", University Hospital G. Martino, Via C. Valeria 1, 98125 Messina, Italy
5 Faculty of Medicine, College of Medicine, Kaohsiung Medical University, Kaohsiung, Taiwan

6 Department of Otorhinolaryngology-Head and Neck Surgery, College of Medicine, Kaohsiung Medical University, Kaohsiung, Taiwan

7 Department of Surgery and Department of Morphology, Surgery and Experimental Medicine, S. Anna University Hospital and University of Ferrara, Ferrara, Italy

8 Department of Surgical, Medical, Molecular Pathology and Critical Area, University of Pisa, Pisa, Italy

9 Department of Otolaryngology-Head and Neck Surgery, The Johns Hopkins University School of Medicine, Baltimore, MD, USA

10 Department of Surgery, KUMC Thyroid Center, Korea University Hospital, Korea University College of Medicine, Seoul, South Korea 


\section{Introduction}

With numerous Institutions beginning to perform transoral endoscopic thyroidectomy vestibular approach (TOETVA), there is an increased interest in new devices that may facilitate training and the surgical procedure, in order to reduce morbidity and conversion rate $[1-14,13 \bullet \bullet, 14-16]$. As a surgeon starts a new procedure, they should use the visual identification of the RLN as well as intermittent intraoperative nerve monitoring to evaluate neurophysiologic integrity to best protect it. The surgeon should endeavor to know the effects of the performance of the new surgical technique on nerve function $[3,17]$. The surgeon should always consider applying at a minimum the same safety principles to TOETVA as applied to conventional surgery [17]. Many surgeons introduced intraoperative nerve monitoring (IONM) during TOETVA to guide RLN identification and functional assessment [18-22]. The purpose of this review is primarily to describe technical tips, and the value of using IONM during TOETVA, with respect given to nerve monitoring standards described by the International Neural Monitoring Study Group (INMSG) [23].

\section{Monitoring Procedure}

IONM should be performed according to standards of equipment setup, induction and maintenance of anesthesia, correct tube positioning verification tests, and EMG definitions described by the INMSG [23, 24].

\section{Team}

The use of IONM in TOETVA requires specialized training [24]. Both the surgeon and anesthesiologist should be familiar with neural monitoring standards, necessary equipment, troubleshooting algorithms, and IONM limits and failures. It is unwise to use monitoring for the first time during TOETVA, without any prior IONM experience [25, 26, 27••, 28•, 29, 30•, 32, 33].

\section{Preoperative Care}

Pre- (L1) and postoperative (L2) laryngeal examination should be routinely performed in all TOETVA patients candidates [23-25]. L1 and L2 exams are recommended in all cases of TOETVA to truly understand the rates of vocal fold motion impairment form this relatively new operation. Furthermore, if you intend to use IONM, L1 is a reference for RLN predissection stimulation (R1). L2 is a reference for RLN postdissection stimulation (R2) [23-25].

\section{Operating Room Setup}

The IONM monitor is placed in an area where it can be easily visualized by the operating room team (Fig. 1). This setup allows for an easy, continuous, and simultaneously display of EMG data together with the endoscopic intraoperative surgical view, without any distraction for the surgeon [20-26, $27 \bullet \bullet, 28 \bullet, 29,30 \bullet, 31-33]$.

\section{Patient Information About IONM}

IONM is mentioned in the preoperative informed consent for TOETVA. The possibility to stage the procedure in case of an EMG loss of signal (LOS) on the initially operated dominant side may be specified in the preoperative informed consent $[23,24]$. As for any technology when used, the possibility of failure of IONM technology (malfunction, accuracy, etc.) should be detailed to the patient [24].

\section{Induction and Maintenance of Anesthesia}

Generally, about $30 \mathrm{~min}$ are required to create the working space from the mouth into the neck, the medial mobilization of the thyroid lobe, and thus the safe access to the vagal nerve (VN) [22-26, 27••, 28•, 29, 30•, 31-33]. It is essential to have full muscular activity return as soon as the dissection achieves the $\mathrm{VN}$ for $\mathrm{V} 1$ stimulation (i.e., pre-dissection VN stimulation). A single dose of a non-depolarizing muscle relaxant (e.g., rocuronium and atracurium at $0.3 \mathrm{mg} / \mathrm{kg}$ ) or succinylcholine at 2 to $2.5 \mathrm{mg} / \mathrm{kg}$ may be used at intubation to allow for the normal return of spontaneous respiration and resumption of normal muscle twitch activity within several minutes [23, 24].

\section{EMG Recording Site}

Nerve-monitoring formats other than via an endotracheal tube with electrodes for vocal fold monitoring are difficult to use in any endoscopic thyroid procedure [21-24]. Thus, for safety, utility, and simplicity, systems that rely on endotracheal tubebased surface electrodes have become the preferred monitoring equipment for TOETVA $[25,26,27 \bullet \bullet, 28 \bullet, 29,30 \bullet$, 31-33].

\section{Oro-tracheal vs. Naso-tracheal Intubation}

TOETVA is performed under general anesthesia with naso- or

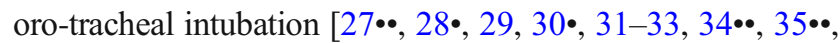
$36 \bullet \cdot$. There are no contraindications to the oro-tracheal intubation for TOETVA [33]. The endotracheal tube although in the oral area, is secured to the upper lip and, therefore does not interfere with the surgical maneuvers during TOETVA [33]. It is always useful to verify and ensure the correct position of the endotracheal tube and then to secure its position [33]. The 
Fig. 1 An area where the IONM monitor can be easily visualized by the operating room team
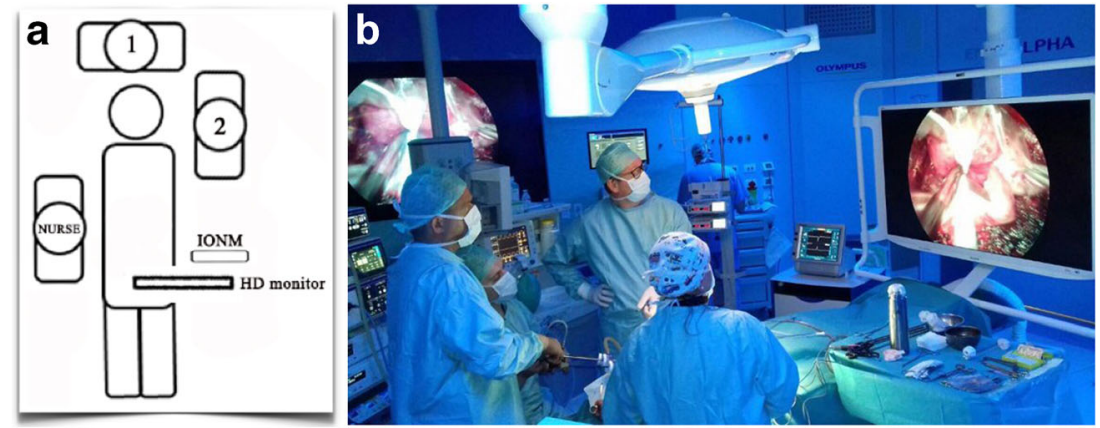

TOETVA surgeon must always consider (a) current unknown prevalence of EMG tube displacement in TOETVA, both for oral- and naso-tracheal intubation. (b) Teamwork with the anesthesiologist should help to develop a standardized tube placement algorithm. (c) It is important that the correct position of the EMG tube has been verified by laryngoscopy and if possible after final positioning of the patient head [33].

\section{Stimulating Probes}

Four different tools can be applied (Fig. 2): (A) single use, 230-mm ball tip long stimulation probe, monopolar; (B) single use, incrementing prass stimulating probe, monopolar, standard flexible tip; (C) single use, single electrode needle flexible wire, $13 \mathrm{~mm} \times 27 \mathrm{ga}, 230 \mathrm{~cm}$ length; (D) curved bipolar Maryland dissector forceps, $5 \mathrm{~mm} \times 42 \mathrm{~cm}$, insulated metal with adapter to the IONM connecting box [33]. There is insufficient data in the current literature to comment as to which a stimulating electrode type is preferable for endoscopic thyroidectomy, and in particular for TOETVA [27••, 28•, 29, 30•, $31-33,34 \bullet \bullet, 35 \bullet \bullet, 36 \bullet \cdot$. It is important to use a long sterile, covered stimulating probe that from the oral cavity reaches the neck for both the right and left RLN and VN determinations. The ideal length of the stimulator should be $300 \mathrm{~mm}$ long with a connection cable. The stimulating probe may also be configured with an atraumatic tip on the dissecting instruments

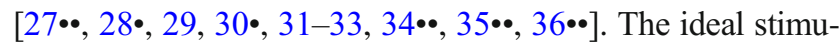
lating probe should be sterile, covered, thin in diameter $(<$ $5 \mathrm{~mm}$ ), not bulky, wireless, malleable, atraumatic tip (ball tip), easy to grip, and safe. Commonly, the right 5-mm port is used for a stimulating probe positioning (Fig. 3).

\section{Standardized Procedure}

According to literature, standardized IONM procedure can be accomplished with V1, R1, V2, and R2 determinations [27••,

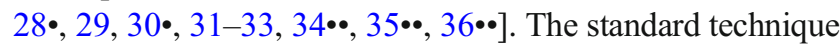
is to stimulate both the $\mathrm{VN}$ and the RLN before and after thyroid resection [23]. V1 is for reference to the thyroid dissection and for RLN identification. V1 determination should proceed with the thyroid dissection. A negative EMG response indicates a non-nerve structure or altered function of the RLN. IONM provides important prognostic information regarding ipsilateral vocal cord function at the completion of
Fig. 2 Stimulating probes with four different tools
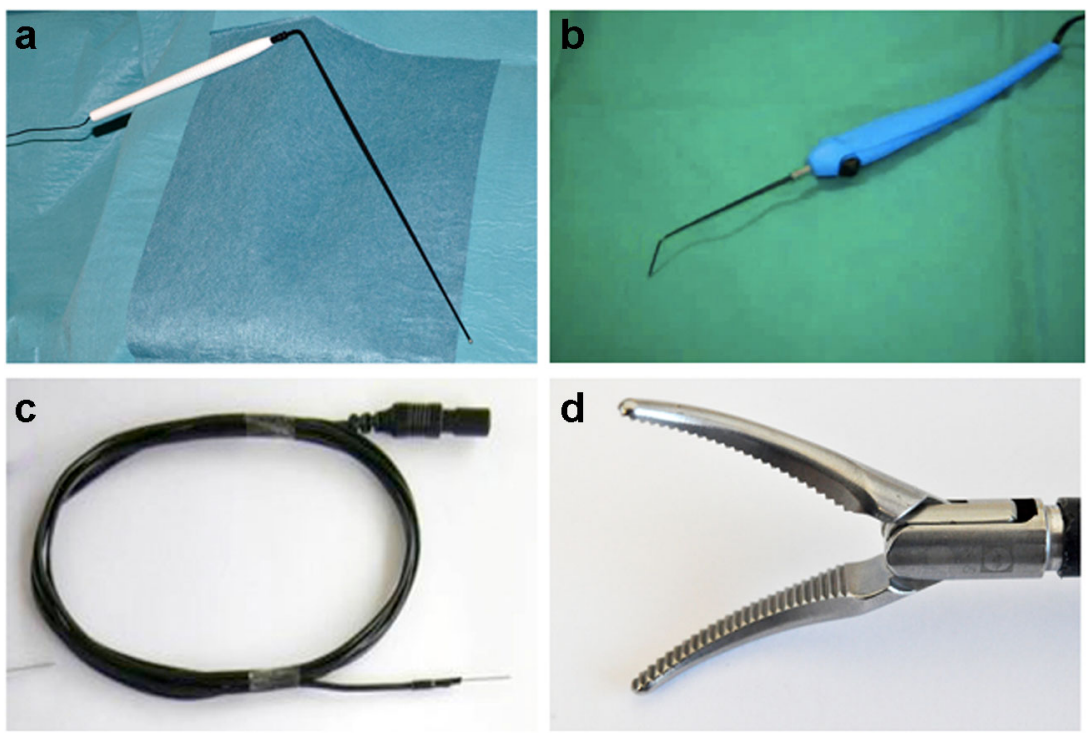

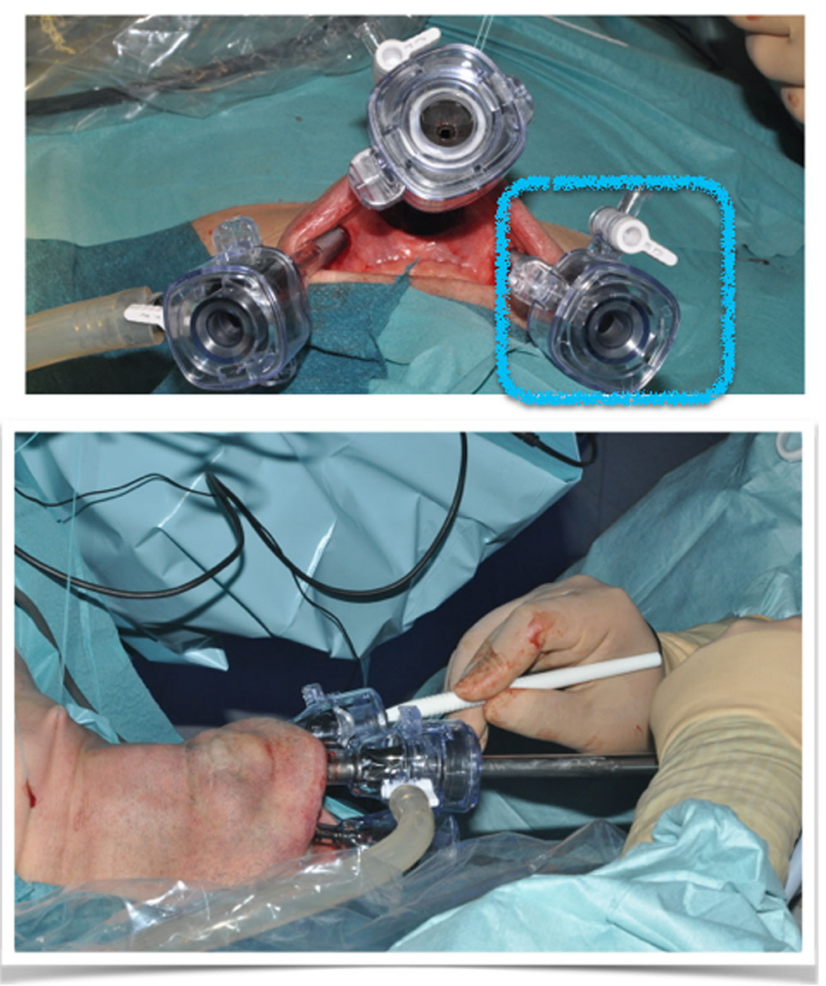

Fig. 3 The ideal stimulating probe should be sterile, covered, thin in diameter, not bulky, wireless, malleable, atraumatic tip (ball tip), easy to grip, and safe. The right $5-\mathrm{mm}$ port is used for a stimulating probe positioning

the initial side of the TOETVA surgery. Direct RLN stimulation (both R1 and R2) is performed with a 1-mA setting. V1 and V2 were performed without opening the carotid sheet, just increasing to $2-3 \mathrm{~mA}$ the probe stimulation intensity, and applying the probe gently, on the carotid sheet without dissection.

\section{Troubleshooting Algorithm: Limits in TOETVA}

Given the potential impact that loss of signal (LOS) may have on the surgical plan (i.e., aborting the second side surgery), it is critical that the surgeon who uses IONM is perfectly experienced in LOS troubleshooting algorithms [23]. The International IONM study group recommends adding either laryngeal twitch or contralateral vagal nerve stimulation assessments to the noted EMG data [23]. A significant limit for applying the proposed troubleshooting algorithm to monitored transoral surgery is determined by the (a) inability to appreciate the laryngeal twitch by digital palpation and (b) the difficulty in stimulating the contralateral vagal nerve without further surgical dissection. EMG tube malposition is the most frequent cause of IONM malfunction (Fig. 4).

\section{Documentation}

Especially, at this early stage of TOETVA adoption, EMG data recording is crucial so that we may precisely understand the effect on the RLN and voice outcomes. EMG signals can be easily recorded and printed out to be filed for future reference [21-24]. The INMSG suggests the recording of timed EMG waveforms including measures of amplitude, latency, waveform morphology, and magnitude of stimulating current at the beginning and completion of surgery for ipsilateral RLN and $\mathrm{VN}$ [23].

\section{Essay}

\section{Intermittent IONM}

There are few technical reports of TOETVA with the use of IONM $[13 \bullet \bullet, 27 \bullet \bullet, 34 \bullet, 35 \bullet, 36 \bullet \cdot$. Authors agreed IONM serves as an adjunct to the endoscopic identification of RLN $[13 \bullet \bullet, 27 \bullet, 34 \bullet, 35 \bullet, 36 \bullet$ ]. Witzel and Benhidjeb first tested the feasibility of the transoral access for thyroid resection including intermittent monitoring for the RLN in 10 living pigs in 2009 [34••]. Ten endoscopic sublingual transoral thyroidectomies were performed using a neuromonitoring system with a long stimulating probe. The RLNs were identified visually and then confirmed with the neuromonitoring system at the beginning (R1) and at the end of the bilateral procedures (R2) [34••]. Inabnet WB et al. provide a step-by-step video overview of TOETVA for a right toxic 4-cm thyroid nodule and demonstrate how to set up and utilize intraoperative nerve monitoring [13••]. The case included naso-tracheal intubation with an EMG tube, the use of a laparoscopic Maryland dissecting forceps as the stimulating probe, R1 and R2 determinations with amplitude signal above $500 \mu \mathrm{V}[13 \cdot 0]$. Wang et al. first proposed a detailed description of a standardized technique for identification and assessing the function of laryngeal nerves with IONM during TOETVA: the RLN (R1 and R2) and vagus nerve (V1 and V2) were both stimulated before and after thyroid resection to prove RLN integrity [35*0]. Wang report included 10 patients with thyroid carcinoma who received monitored TOETVA and central node dissection [35••]. IONM was implemented by oral-tracheal intubation, percutaneous stimulating probe and standardized technique with V1, R1, R2, and V2 stimulations [35••]. Again, it is important to emphasize that the authors suggest using a reinforced oro-endotracheal tube that permits nerve monitoring and that stimulation of the vagus and RLN's can be done through one of the working ports. 
Fig. 4 Troubleshooting algorithm

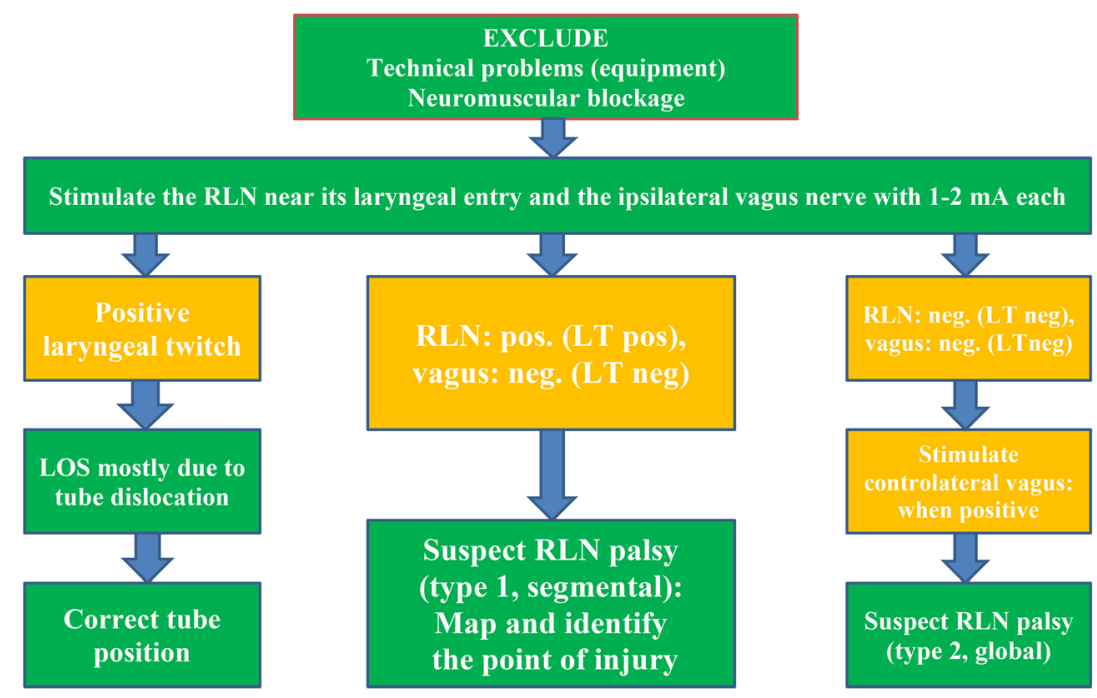

\section{Continuous IONM}

Zhang et al. first evaluated the feasibility of continuous intraoperative neural monitoring (C-IONM) in TOETVA in an experimental model $[27 \bullet \bullet]$. Duroc-Landrace pigs were orally intubated with the EMG endotracheal tube. The automatic periodic stimulation (APS) electrode was placed in the operative field through the 5-mm ports [27••]. APS electrode was then positioned on the VN with 2 different approaches: (a) median, that is, between sternothyroid and thyroid gland; and (b) lateral, that is, between the sternocleidomastoid and sternothyroid. The VN was stimulated proximally and distally to the APS location to verify whether the dissection and/or placement resulted in VN injury. Assembled APS accessory resulted feasible in animal models with dimension of the head comparable to humans (large-brained animals) [27••]. Baseline amplitude values obtained were $>1000 \mu \mathrm{V}$, bilaterally. The author concluded that C-IONM was feasible in TOETVA in porcine models, but a simplification of the electrode design and the application process is needed [27••]. Chen et al. first reported on the use of CIONM in TOETVA, using a dedicated monitor (monitor C2) and delta stimulating electrode in a clinical setting [36••]. The stimulating electrode was transorally inserted, with its cable line lying outside the trocar [36••]. The VN was gently dissected, looped, and then enveloped by the electrode cuff in 28 nerves at risk [36••]. All C-IONM procedures were successfully completed. In all patients, the stimulation was set at 0.7 -milliamps every $1 \mathrm{~s}$, and C-IONM use was not associated with any untoward neural, cardiovascular, or gastrointestinal sequelae. On average, the ipsilateral C-IONM procedure required $10.33 \pm 2.57 \mathrm{~min}$ to complete. This time it fits, during the procedure, in the period between contralateral retraction of the thyroid gland and complete placement of the delta electrode on the vagal nerve.

Except for one instance, no significant problems occurred with electrode displacement. In one patient, a combined EMG event occurred, which improved after releasing the thyroid retractor, and the patient had no vocal cord paralysis postoperatively $[36 \bullet \bullet]$.

\section{Conclusion}

IONM implemented in TOETVA is feasible and helpful in identifying and confirming the neurophysiologic status of the RLN. With transoral access, the identification of the recurrent laryngeal nerve is at its entrance into the larynx (cricothyroid insertion point); thus, the surgical dissection of the laryngeal nerve is cranial to caudal. IONM may be especially helpful for new adopters of TOETVA since this approach to finding the RLN may not be common during open thyroid surgery novel. IONM enables testing the RLN function (i.e., monitoring) and corrective action at three stages of surgery: (a) during blunt dissection, (b) using energy-based devices, and (c) while there is thyroid gland or tracheal retraction. IONM also provides a helpful evaluation of RLN function on the first side of a planned total thyroidectomy before proceeding to the contralateral lobe.

Authors' Contributions All authors equally contributed to the conception, design, manuscript writing, and final approval of the manuscript.

Availability of Data and Materials The datasets used and/or analyzed during the current study are available from the corresponding author on reasonable request.

\section{Compliance with Ethical Standards}

Conflict of Interest The authors declare that they have no conflict of interest.

Human and Animal Rights and Informed Consent This article does not contain any studies with human or animal subjects performed by any of the authors. 


\section{References}

Papers of particular interest, published recently, have been highlighted as:

- Of importance

- Of major importance

1. Witzel K, von Rahden BH, Kaminski C, Stein HJ. Transoral access for endoscopic thyroid resection. Surg Endosc. 2008;22(8):1871-5.

2. Benhidjeb T, Wilhelm T, Harlaar J, Kleinrensink GJ, Schneider TA, Stark M. Natural orifice surgery on thyroid gland: totally transoral video-assisted thyroidectomy (TOVAT): report of first experimental results of a new surgical method. Surg Endosc. 2009;23(5):111920. https://doi.org/10.1007/s00464-009-0347-0.

3. Wilhelm T, Metzig A. Video. Endoscopic minimally invasive thyroidectomy: first clinical experience. Surg Endosc. 2010;24(7): 1757-8. https://doi.org/10.1007/s00464-009-0820-9.

4. Wilhelm T, Metzig A. Endoscopic minimally invasive thyroidectomy (eMIT): a prospective proof-of-concept study in humans. World J Surg. 2011;35(3):543-51. https://doi.org/10.1007/s00268-0100846-0.

5. Anuwong A. Transoral endoscopic thyroidectomy vestibular approach: a series of the first 60 human cases. World J Surg. 2016;40(3):491-7.

6. Liu E, Qadir Khan A, Niu J, Xu Z, Peng C. Natural orifice total transtracheal endoscopic thyroidectomy surgery: first reported experiment. J Laparoendosc Adv Surg Tech A. 2015;25(7):586-91.

7. Woo SH. Endoscope-assisted transoral thyroidectomy using a frenotomy incision. J Laparoendosc Adv Surg Tech A. 2014;24(5):345-9.

8. Benhidjeb T, Stark M. Endoscopic minimally invasive thyroidectomy (eMIT): safety first! World J Surg. 2011;35(8):1936-7.

9. Clark JH, Kim HY, Richmon JD. Transoral robotic thyroid surgery. Gland Surg. 2015;4(5):429-34.

10. Lee HY, Richmon JD, Walvekar RR, Holsinger C, Kim HY. Robotic transoral periosteal thyroidectomy (TOPOT): experience in two cadavers. J Laparoendosc Adv Surg Tech A. 2015;25(2): 139-42.

11. Lee HY, You JY, Woo SU, Son GS, Lee JB, Bae JW, et al. Transoral periosteal thyroidectomy: cadaver to human. Surg Endosc. 2015;29(4):898-904.

12. Lee HY, Hwang SB, Ahn KM, Lee JB, Bae JW, Kim HY. The safety of transoral periosteal thyroidectomy: results of Swine models. J Laparoendosc Adv Surg Tech A. 2014;24(5):312-7.

13.• Inabnet WB 3rd, Suh H, Fernandez-Ranvier G. Transoral endoscopic thyroidectomy vestibular approach with intraoperative nerve monitoring. Surg Endosc. 2017;31(7):3030. https://doi.org/10. 1007/s00464-016-5322-y Video provides a step-by-step overview of TOETVA and demonstrate how to set up and utilize intraoperative nerve monitoring.

14. Park JO, Kim MR, Kim DH, Lee DK. Transoral endoscopic thyroidectomy via the trivestibular route. Ann Surg Treat Res. 2016;91(5):269-72.

15. Witzel K, Hellinger A, Kaminski C, Benhidjeb T. Endoscopic thyroidectomy: the transoral approach. Gland Surg. 2016;5(3):336-41. https://doi.org/10.21037/gs.2015.08.04.

16. Udelsman R, Anuwong A, Oprea AD, Rhodes A, Prasad M, Sansone M, et al. Trans-oral vestibular endocrine surgery: a new technique in the United States. Ann Surg. 2016;264(6):e13-6.

17. Dralle H. Impact of modern technologies on quality of thyroid surgery. Langenbeck's Arch Surg. 2006;391(1):1-3.

18. Dionigi G, Lavazza M, Bacuzzi A, Inversini D, Pappalardo V, Tufano RP, et al. Transoral endoscopic thyroidectomy vestibular approach (TOETVA): from A to Z. Surg Technol Int. 2017;30: $103-12$.

19. Dionigi G, Bacuzzi A, Lavazza M, Inversini D, Pappalardo V, Boni L, et al. Transoral endoscopic thyroidectomy via vestibular approach: operative steps and video. Gland Surg. 2016;5(6):625-7. https://doi.org/10.21037/gs.2016.12.05.

20. Dionigi G, Tufano RP, Russell J, Kim HY, Piantanida E, Anuwong A. Transoral thyroidectomy: advantages and limitations. J Endocrinol Investig. 2017;40(11):1259-63. https://doi.org/10. 1007/s40618-017-0676-0.

21. Dionigi G, Bacuzzi A, Lavazza M, Inversini D, Boni L, Rausei S, et al. Transoral endoscopic thyroidectomy: preliminary experience in Italy. Updat Surg. 2017;69(2):225-34. https://doi.org/10.1007/ s13304-017-0436-x.

22. Dionigi G, Rovera F, Boni L. Commentary on transoral access for endoscopic thyroid resection : Witzel K, von Rahden BH, Kaminski C, Stein HJ (2008) Transoral access for endoscopic thyroid resection. Surg Endosc 22(8):1871-1875. Surg Endosc. 2009;23(2):454 5; discussion 456. https://doi.org/10.1007/s00464-008-0241-1.

23. Randolph GW, Dralle $H$, International Intraoperative Monitoring Study Group, Abdullah H, Barczynski M, Bellantone R, et al. Electrophysiologic recurrent laryngeal nerve monitoring during thyroid and parathyroid surgery: international standards guideline statement. Laryngoscope. 2011;121:S1-16.

24. Dionigi G, Boni L, Rovera F, Bacuzzi A, Dionigi R. Neuromonitoring and video-assisted thyroidectomy: a prospective, randomized case-control evaluation. Surg Endosc. 2009;23(5): 996-1003. https://doi.org/10.1007/s00464-008-0098-3.

25. Dionigi G, Boni L, Rovera F, Rausei S, Castelnuovo P, Dionigi R. Postoperative laryngoscopy in thyroid surgery: proper timing to detect recurrent laryngeal nerve injury. Langenbeck's Arch Surg. 2010;395(4):327-31. https://doi.org/10.1007/s00423-009-0581-x.

26. Russell JO, Anuwong A, Dionigi G, Inabnet WB 3rd, Kim HY, Randolph G, et al. Transoral thyroid and parathyroid surgery vestibular approach: a framework for assessment and safe exploration. Thyroid. 2018. https://doi.org/10.1089/thy.2017.0642.

27.• Zhang D, Li S, Dionigi G, Wang T, Zhang J, Xue G, et al. Feasibility of continuous intraoperative neural monitoring during transoral endoscopic thyroidectomy vestibular approach in a porcine model. J Laparoendosc Adv Surg Tech A. 2018. https://doi. org/10.1089/lap.2018.0054 Experimental study to evaluate feasibility of continuous intraoperative neural monitoring $(C$ IONM) in transoral endoscopic thyroidectomy vestibular approach.

28. Sun H, Anuwong A, Dionigi G. The value of neural monitoring in endoscopic-robotic thyroidectomy approaches. J Minim Access Surg. 2018. https://doi.org/10.4103/jmas.JMAS_273_17 IONM enable surgeons to feel more comfortable with their initial approach to TOETVA or extended indications.

29. Sun H, Dionigi G. Additions of neural monitoring for thyroid surgery. Endocrine. 2018;61:547. https://doi.org/10.1007/s12020-0181565-9.

30. Dionigi G, Wu CW, Tufano RP, Rizzo AG, Anuwong A, Sun H, et al. Monitored transoral endoscopic thyroidectomy via long monopolar stimulation probe. J Vis Surg. 2018;4:24. https://doi. org/10.21037/jovs.2017.12.25 eCollection 2018. Video describes the usefulness of intraoperative neuromonitoring during transoral endoscopic thyroidectomy vestibular approach.

31. Sun H, Wu CW, Kim HY, Dionigi G. Neural monitoring represent central safety asset for new technologies in thyroid surgery in translational protocols. Am J Surg. 2018. https://doi.org/10.1016/j. amjsurg.2018.01.022.

32. Chai YJ, Kim HY, Kim HK, Jun SH, Dionigi G, Anuwong A, et al. Comparative analysis of 2 robotic thyroidectomy procedures: transoral versus bilateral axillo-breast approach. Head Neck. 2018;40(5):886-92. https://doi.org/10.1002/hed.25034. 
33. Dionigi G, Chai YJ, Tufano RP, Anuwong A, Kim HY. Transoral endoscopic thyroidectomy via a vestibular approach: why and how? Endocrine. 2018;59(2):275-9. https://doi.org/10.1007/ s12020-017-1451-x.

34.• Witzel K, Benhidjeb T. Monitoring of the recurrent laryngeal nerve in totally endoscopic thyroid surgery. Eur Surg Res. 2009;43(2):726. https://doi.org/10.1159/000220596 Feasibility of the sublingual transoral access for thyroid resection including the monitoring of the recurrent laryngeal nerve in a porcine model.

35.. Wang Y, Yu X, Wang P, Miao C, Xie Q, Yan H, et al. Implementation of intraoperative neuromonitoring for transoral endoscopic thyroid surgery: a preliminary report. J Laparoendosc Adv Surg Tech A. 2016;26(12):965-71 Standardized IONM applied in TOETVA.
36.• Chen HK, Chen CL, Wen KS, Lin YF, Lin KY, Uen YH. Application of transoral continuous intraoperative neuromonitoring in natural orifice transluminal endoscopic surgery for thyroid disease: a preliminary study. Surg Endosc. 2018;32(1): 517-25. https://doi.org/10.1007/s00464-017-5656-0 C-IONM is feasible and safe to use during transoral endoscopic thyroidectomies and may assist in the early detection of adverse EMG changes, thereby preventing paralysis of the RLNs.

Publisher's note Springer Nature remains neutral with regard to jurisdictional claims in published maps and institutional affiliations. 